\title{
THE LAWS OF TRANSPLANTATION: A MODERN PERSPECTIVE
}

\author{
J. RICHARD BATCHELOR \\ London
}

The general law of transplantation which states that an allograft is only accepted provided that it does not express histocompatibility genes that are foreign to the recipient was formulated over 60 years ago. The law was based on the results of experiments with tumour allografts, chiefly in mice. Subsequently, similar work on the fate of skin allografts did not disturb these early concepts. However, when transplantation was extended to vascularised organs, a number of exceptions to the general law have been revealed. For example, orthotopic liver transplants in many donor/recipient combinations known to differ at the major histocompatibility complex (MHC) may escape graft destruction. ${ }^{1,2}$ Although there are fewer, documented examples of the same phenomenon occurring with normal, incompatible kidneys, they do exist. ${ }^{3,4}$ There is also the case of orthotopic rat kidney allografts that have been 'parked' temporarily in a primary recipient, under immunosuppressive cover to prevent rejection, before being retransplanted into an untreated second recipient, genotypically identical to the first recipient. Such kidneys lose the strong immunogenicity characteristic of normal kidney allografts and in many, but not all, donor/recipient combinations they are accepted by the second recipient, ultimately rendering them specifically tolerant. ${ }^{5}$

Studies on this experimental model of a kidney allograft depleted of incompatible passenger leucocytes showed that the cell responsible for endowing a normal kidney with its characteristic, strong immunogenicity is the dendritic cell. ${ }^{6,7}$ To account for the variation in the fate of passenger cell depleted kidney allografts in different inbred strain combinations, it was proposed that there are two sets of T cells taking part in graft rejection. These two sets have different immunological specificity, are activated by different populations of antigen presenting cells, and have different destructive potency. ${ }^{6}$

Correspondence to: J. R. Batchelor, Department of Immunology, Royal Postgraduate Medical School, Hammersmith Hospital, Du Cane Road, London W12 0NN, UK.
The purpose of this paper is to develop this theme further, showing how it may help to explain two significant phenomena of transplantation biology. The first is the difference in vulnerability of different solid tissues to rejection, and the second is the change in vulnerability of a given organ allograft to rejection with increasing time after transplantation.

\section{THE TWO PATHWAYS OF SENSITISATION TO MHC INCOMPATIBLE TISSUES: DIRECT AND INDIRECT}

CD4+ T lymphocytes of the graft recipient activated by the direct pathway are those cells that are triggered by class II MHC molecules expressed by allogeneic dendritic cells present in the graft. They are not self-MHC-restricted. Studies on mixed lymphocyte cultures (MLC) have shown that the sole cells responsible for primary stimulation in vitro are dendritic cells. ${ }^{8,9}$ On the other hand, $T$ lymphocytes of the indirect pathway are those triggered by antigen presenting cells (APC) of recipient origin that have internalised molecules derived from the graft, processed them, and presented them as peptides bound to recipient class II MHC molecules. Thus $\mathrm{T}$ cells of the indirect pathway are self-MHC-restricted, and have different immunological specificity to cells of the direct pathway.

An issue of considerable significance is that in nonsensitised recipients the frequencies of $T$ cells of the two pathways are very different. Estimates of the number of $\mathrm{T}$ cells responding in MLC indicate that $5-10 \%$ of the total pool of peripheral $\mathrm{T}$ cells undergo proliferation. It is thought that all of these are direct pathway $\mathrm{T}$ cells because removal of the allogeneic dendritic cells from the stimulating population renders the MLC non-reactive. In contrast, selfMHC-restricted $\mathrm{T}$ cells of any immunological specificity are not found in non-sensitised subjects, and can only be demonstrated after antigenic priming of the host. In consequence it is presumed 
that $\mathrm{T}$ cells of the indirect pathway are at least $2 \log$ orders of magnitude less frequent in non-sensitised subjects. Therefore, in non-sensitised individuals direct pathway $\mathrm{T}$ cells are expected to dominate early rejection. However, as a graft recipient becomes sensitised, there is no theoretical reason why indirect pathway $\mathrm{T}$ cells should not play an increasingly active part in mediating late damage to the allograft.

Another difference that is predicted to distinguish $\mathrm{T}$ cells of the two pathways is their clonality. The high frequency of direct pathway cells can only be reconciled by the assumption that the population is very polyclonal. Indirect pathway cells, being selfMHC-restricted, are likely to be of more limited clonality since only a fraction of peptides derived from an allograft may bind to the recipient's class II MHC molecules.

At the time that the above hypothesis was proposed, self-MHC-restricted $\mathrm{T}$ cells recognising peptides derived from allogeneic MHC molecules had not been demonstrated, nor had their possible role in graft rejection been investigated. This has now changed. Human, rat and mouse T cells with these properties have been generated in vitro, and there is evidence from Fabre's laboratory ${ }^{10,11}$ and Carpenter's $^{12}$ that they are involved in the rejection of rat organ and skin allografts, and provide 'help' to B cell clones that synthesise anti-MHC alloantibodies.

In my own laboratory, studies on the functional role of $T$ cells of the direct pathway in rat kidney allograft rejection have shown that these cells are remarkably potent in initiating rejection of normal allogeneic kidneys; however, they fail to cause rejection once the allogeneic, passenger dendritic cells have left the graft. ${ }^{13}$ The reason for the failure of the direct pathway $\mathrm{T}$ cells to effect rejection of dendritic cell depleted kidneys is not because the target organ does not express rat class II MHC antigens. Immunohistological studies have demonstrated these antigens on graft tissue, and this has been confirmed in cell fluorimetric analyses of renal epithelial cells grown in vitro. The explanation appears to be that the direct pathway $\mathrm{T}$ cells are rendered immunologically anergic when confronted by non-dendritic cells expressing the relevant class II MHC molecules. ${ }^{14}$ Although this is merely a speculation, I suggest that the reason why anergy is induced is that the cells of the allograft expressing allogeneic class II polymorphisms fail to provide the co-stimulating signals required to activate the direct pathway $\mathrm{T}$ cells.

Let us now consider how the concept of two different populations of $\mathrm{T}$ cells (direct and indirect pathway) offers a logical explanation for some of the previously enigmatic variations in behaviour of MHC incompatible allografts.
It is well known that the amount of immunosuppression needed to prevent graft rejection changes with time after transplantation. It is only to be expected that immediately after transplantation, the highly polyclonal, direct pathway $\mathrm{T}$ cell population would require an aggressive immunosuppressive regimen; however, as the allogeneic dendritic cells are lost from the graft, there would be a corresponding loss of activation stimulus for the direct pathway $T$ cells, which would become anergic instead. In these circumstances, the fate of the graft would depend on the destructive potential of the expanding population of indirect pathway $\mathrm{T}$ cells. Since this population is likely to have been extremely small to start with in the previously non-sensitised recipient, lower doses of immunosuppressive drugs would be needed to prevent graft damage.

Acute rejection occurring early after transplantation differs in clinical and pathological features from chronic or late rejection. These differences could be well explained by attributing the early rejection episodes to direct pathway $\mathrm{T}$ cells and late/chronic rejection to the indirect pathway cells.

Matching of donor and recipient for MHC polymorphisms would be expected to have different effects on the cells of the two pathways. Activation of direct pathway $\mathrm{T}$ cells would be expected to be minimised by matching for class II antigens. This would tend to prevent early graft rejection. On the other hand, matching for class II would provide circumstances which allowed self-MHC-restricted $\mathrm{CD} 4+\mathrm{T}$ cells of the indirect pathway to interact with cells of the allograft, which may not be beneficial to the survival of the graft. It has already been demonstrated that donor/recipient matching for HLA-DR antigens is beneficial for the survival of kidney allografts during the first year after transplantation, but that the matching has little effect subsequently. ${ }^{14}$

Variations in the vulnerability of a tissue to allograft rejection would be expected to depend, amongst other factors, on the number and properties of the passenger dendritic cells found in that tissue. Tissues lacking these cells would fail to trigger the direct pathway $\mathrm{T}$ cells, and whether rejection occurred would depend on the indirect pathway. This presumably is one of the reasons why corneal grafts of $8 \mathrm{~mm}$ diameter and less are rarely rejected in non-vascularised graft beds.

\section{OPERATIONAL TOLERANCE}

One further matter of great importance is the induction of immunological non-responsiveness in the direct and indirect $\mathrm{T}$ cell populations. There is no reason to expect that the mechanisms of nonresponsiveness would be the same for $T$ cells of both pathways. The evidence from my own labora- 
tory indicates that $\mathrm{T}$ cells of the direct pathway are rendered anergic because they are confronted by allo-class II molecules on graft cells, unable to provide all the co-stimulatory signals necessary for activation. However, the position is entirely different for the indirect pathway. In this case, professional APC of the recipient are in abundance, and can continue indefinitely to present peptides derived from the allograft. There is therefore no likelihood that indirect pathway $\mathrm{T}$ cells would become anergised. It is interesting that in all the examples of the successful adoptive transfer of suppressor cells, the experimental conditions are such that the suppressive action is effected on $\mathrm{T}$ cells likely to be of the indirect pathway. I conclude that the phenomenon of suppressor cells, whatever its molecular basis, is confined to down-regulating indirect pathway (selfMHC-restricted) $\mathrm{T}$ cells.

\section{CONCLUSIONS}

I offer a modern version of the laws of transplantation:

1. In previously non-immunised recipients, the high frequencies of $\mathrm{T}$ cells capable of responding (by the direct pathway of sensitisation) to MHC incompatible dendritic cells results in these $T$ cells becoming the dominant population mediating acute allograft rejection, provided that significant numbers of allogeneic dendritic cells are present in the target tissue.

2. Once the passenger (allogeneic) dendritic cells migrate out of the allograft, direct pathway $\mathrm{T}$ cells entering the graft are rendered anergic, presumably because their antigen receptor binds to alloantigen but no 'second signal' is provided. This is a major factor in the development of operational tolerance or near tolerance to organ allografts.

3. Chronic or late rejection has different clinical and pathological features to early, acute rejection, and it is predicted that the dominant $\mathrm{T}$ cells participating in this form of rejection are those sensitised by the indirect pathway. (An urgent task facing transplantation immunologists is to devise suitable methods for identifying and measuring the numbers of these cells.)

4. Matching the MHC type of donor to recipient would only be expected to improve graft survival in those circumstances where graft destruction is mediated by $\mathrm{T}$ cells of the direct pathway. We have yet to determine the rules governing differences in the responsiveness of self-MHCrestricted $\mathrm{T}$ cells sensitised by the indirect pathway to peptides derived from allogeneic tissues.
5. The well-known variation in susceptibility of different tissues and organs to rejection is predicted to be due to the target tissue's content of indigenous, allogeneic dendritic cells; this is the most influential factor that determines the contribution made by $\mathrm{T}$ cells of the direct pathway to the rejection response.

Key words: Direct pathways, Graft rejection, Indirect pathways, Tolerance.

\section{REFERENCES}

1. Calne RY, Sells RA, Pena JR, et al. Induction of immunological tolerance by porcine liver allografts. Nature 1969;223:472-4.

2. Kamada N, Davies HffS, Wight D, et al. Liver transplantation in rat: biochemical and histological evidence of complete tolerance induction in nonrejector strains. Transplantation 1983;35:304-9.

3. Salaman JR, Elves MW, Festenstein H. Factors contributing to survival of rats transplanted with kidneys mismatched at major locus. Transplant Proc 1971;3:577-9.

4. Skoskiewicz M, Chase C, Winn HJ, Russell PS. Kidney transplants between mice of graded immunogenetic diversity. Transplant Proc 1973;5:721-5.

5. Batchelor JR, Welsh KI, Maynard A, et al. Failure of long surviving, passively enhanced kidney allografts to provoke T-dependent alloimmunity. J Exp Med 1979;150:455-64.

6. Lechler RI, Batchelor JR. Restoration of immunogenicity to passenger cell-depleted kidney allografts by the addition of donor strain dendritic cells. J Exp Med 1982;155:31-41.

7. Lechler RI, Batchelor JR. Immunogenicity of retransplanted rat kidney allografts. J Exp Med 1982; 156:1835-41.

8. Mason DW, Pugh CW, Webb $M$. The rat mixed lymphocyte reaction: roles of a dendritic cell in intestinal lymph and $\mathrm{T}$ cell subsets defined by monoclonal antibodies. Immunology 1981;44:75-83.

9. Steinman RM, Cohn ZA. Identification of a novel cell type in peripheral lymphoid organs of mice. J Exp Med 1.974;139:380-97.

10. Fangmann J, Dalchau R, Fabre JW. Rejection of skin allografts by indirect allorecognition of donor class $I$ major histocompatibility complex peptides. J Exp Med 1992;175:1521-9.

11. Dalchan R, Fangmann J, Fabre JW. Allorecognition of isolated, denatured chains of class I and II major histocompatibility molecules. Eur J Immunol 1992; 22:669-77.

12. Sayegh MH, Watschinger B, Carpenter CB. Mechanisms of $\mathrm{T}$ cell recognition of alloantigens: the role of peptides. Transplantation 1994;57:1295-302.

13. Braun MY, McCormack A, Webb G, Batchelor JR. Mediation of acute but not chronic rejection of MHCincompatible rat kidney grafts by the direct pathway of sensitisation. Transplantation 1993;55:177-82.

14. Braun MY, McCormack A, Webb G, Batchelor JR. Evidence for clonal anergy as a mechanism responsible for the maintenance of transplantation tolerance. Eur J Immunol 1993;23:1462-8. 